\title{
Endoscopic Third Ventriculostomy versus Ventriculo-Peritoneal Shunt for Infant Hydrocephalus
}

\author{
Khaled Ismail Abdel-Aziz ${ }^{1}$, Radwan Nouby ${ }^{2}$, Mahmoud Ahmed Thabet ${ }^{1}$, \\ Mohammad Fekry Elshirbiny ${ }^{1}$ \\ ${ }^{1}$ Department of Neurosurgery, Faculty of Medicine, Aswan University, Aswan, Egypt \\ ${ }^{2}$ Department of Neurosurgery, Faculty of Medicine, Assiut University, Assiut, Egypt \\ Email: *khaledis2020@yahoo.com
}

How to cite this paper: Abdel-Aziz, K.I., Nouby, R., Thabet, M.A. and Elshirbiny, M.F. (2020) Endoscopic Third Ventriculostomy versus Ventriculo-Peritoneal Shunt for Infant Hydrocephalus. Open Journal of Modern Neurosurgery, 10, 193-202.

https://doi.org/10.4236/ojmn.2020.102020

Received: December 2, 2019

Accepted: January 28, 2020

Published: January 31, 2020

Copyright $\odot 2020$ by author(s) and Scientific Research Publishing Inc. This work is licensed under the Creative Commons Attribution International License (CC BY 4.0).

http://creativecommons.org/licenses/by/4.0/

(c) (i) Open Access

\begin{abstract}
Introduction: Patients with hydrocephalus, which is the most pediatric neurological disorder, undergo Cerebrospinal fluid (CSF) diversion through third ventriculostomy or ventriculo-peritoneal shunt. Up to date, the optimal hydrocephalus treatment modality is not clear. Aim: We compared the outcome of endoscopic third ventriculostomy (ETV) versus ventriculo-peritoneal shunt (VP shunt) as a second surgical intervention in management of Infant hydrocephalus concerning success rate and complications. Patients and Methods: We conducted an observational study of 52 children with hydrocephalus (congenital or acquired) in whom CSF diversion was performed using either ETV or VP shunt in randomized control trial. Results: During the period examined, 52 children, 26 underwent ETV and 26 underwent VP shunt. The mean age was $11.0 \pm 4.3$ months in ETV and $11.3 \pm 4.7$ months in VP shunt. Postoperative infection in the ETV group was lower than in the VP shunt group (23.1\% vs. $53.8 \% \mathrm{P}=0.045)$. Regarding operating time, In ETV group operation duration was $46.9 \mathrm{~min}$ and $64.3 \mathrm{~min}$ in the V-P shunt group $(P=0.13)$. There was no statistically significant difference between the two study groups regarding the rate of obstruction, change in occipital frontal circumference (OFC) or the need of revision surgery. One year survival for VP shunt group vs. ETV group was $46.2 \%$ vs. $65.4 \%$ respectively. Conclusion: ETV associated with lower rates of postoperative infection and shorter operation time with no significant difference in rates of obstruction, change in OFC and revision surgery in comparison to VP shunt.
\end{abstract}

\section{Keywords}

ETV, VPS, Pediatric Hydrocephalus 


\section{Introduction}

Hydrocephalus is one of the most common pediatric neurological diseases [1]. It is estimated congenital hydrocephalus incidence range between 0.5 to 1 case per 1000 births and acquired hydrocephalus is 3 to 5 cases per 1000 births [2].

Cerebrospinal Fluid (CSF) is produced from choroid plexus located within the lateral, third, and fourth ventricles then travel through subarachnoid spaces to be absorbed through arachnoid granulations into the venous sinuses and systemic circulation [3].

Hydrocephalus is a complex medical condition had multiple pathogenesis and classifications. One of commonest classification of hydrocephalus is obstructive versus communicating hydrocephalus. In obstructive type there is blockage in CSF flow. One of the commonest etiologies is aqueductal stenosis and post meningitis [4]. In communicating type there is impairment of CSF reabsorption. Another classifications include Acquired versus developmental (congenital) and syndromic versus non-syndromic [5].

The main treatment of hydrocephalus is the diversion of Cerebrospinal Fluid (CSF). Many diversion techniques developed including shunting techniques through ventriculo-peritoneal (VP) shunt, ventriculo-atrial (VA), lumbo-peritoneal shunt, ventriculo-pleural shunt and endoscopic third ventriculostomy (ETV) [6]. VP shunts used widely but was associated with shunt infection and malfunction includes obstruction, over drainage, under drainage, and occult shunt failure [7].

Over the past two decades ETV gained popularity, compared to shunt, being minimally invasive technique and considered permanent solution for hydrocephalus but was associated with obstruction, infection, CSF leakage, intra-ventricular hemorrhage, and damage to the tuber cinereum with diabetes insipidus [8] [9].

The relative effectiveness between ETV and VPS in children with hydrocephalus is not well established. In this study, we conducted an observational study to investigate the two techniques regarding to success rate, complications, and second surgical intervention in management of infant hydrocephalus.

\section{Patients and Methods}

\subsection{Study Design, Study Setting, and Study Participants}

This study was an observational study on 52 patients with hydrocephalus in the pediatric age group (less than two years of age) whom CSF diversion was performed using either ETV or VP shunt in randomized control trial. Study was conducted at neurosurgery department-Aswan university hospital (between Jan. 2017 to Dec. 2018).

Inclusion criteria: age between 6 months to 2 years, Congenital hydrocephalus, and Post-meningitis hydrocephalus

Exclusion criteria: age less than 6 months and age more than 2 years, patients 
with secondary hydrocephalus due to any cause such as intracranial hemorrhage, subarachnoid hemorrhage (SAH) or any space occupying lesion (SOL).

\subsection{Preoperative Assessments}

All patients underwent baseline investigations including children clinical assessment and manifestation of Hydrocephalus (head circumference is at or above the 98 the percentile for age, dilated scalp veins, tense fontanels, and setting-sun sign). CT scan was done to assess the ventricular dilatation. Criteria to diagnose hydrocephalus was temporal horns above $\geq 2 \mathrm{~mm}$ in width, FH/ID ration above $0: 5$, ballooning of frontal horns of lateral ventricles. Additional MRI was done to detect any malformations.

\subsection{Surgical Procdure}

We used general anesthesia in all operated patients. VP shunt group underwent supine position with roll under shoulder and head tilted to the opposite side. An inverted "C" shaped incision is used to keep hardware from lying directly under the skin incision (minimizes risk of skin breakdown and also creates additional barrier to infection of subjacent hardware).Posterior parital burr hole is used in most cases for insertion site of ventricular catheter, some prefer a frontal burr hole (Kocher's point) citing a lower incidence of failure from choroid plexus occlusion. CSF should be sent for culture at the time of insertion. Peritoneal catheter: A horizontal incision lateral and superior to the umbilicus is one of preferred choices. Tunnling from abdominal incision to cranial incision. Connecting the shunt components with tying them well using silk sutures with ensuring that it's not constricting the shunt at any point. Allow CSF to flow from the distal limb of the shunt to make sure that the shunt is working well. Insert the distal limb in the peritoneal cavity and tie the purce string suture. Closure of scalp wound and abdominal wound in layers. While ETV group, The patient was positioned supine with the head elevated to $20^{\circ}-30^{\circ}$ and with slight flexion of the neck. A bur hole was drilled at Kocher's point, located $3 \mathrm{~cm}$ from the midline and $1 \mathrm{~cm}$ anterior to the coronal suture, approximately along the mid-pupillary line. Pericranial flap should be taken then opening the dura after bipolar cauterization of it. A rigid neuroendoscope (Karl Storz) with a 6-mm sheath, working port, and $1.8-\mathrm{mm}$ telescope was introduced into the lateral ventricle, where the choroid plexus could be seen. Continuous irrigation with lactate ringer solution was started at $5-10 \mathrm{ml} / \mathrm{min}$ and the irrigation speed was increased if required. To keep the third ventricle slightly overfilled, we irrigated for a little while, usually not more than 15 seconds, without letting the fluid out. The irrigation was monitored in the drip chamber. When it slowed or spontaneously stopped, it was assumed that the third ventricle was overfilled and fluid was released through the sheath. The endoscope was advanced through the foramen of Monro into the cavity of the third ventricle, where fenestration was planned The ventricular floor was identified as a bluish transparent membrane in front of the 
mammillary bodies. Safe fenestration of the floor of the third ventricle requires the procedure to be performed in the midline and anterior to the mamillary bodies and the underlying basilar artery apex. Fenestration of the floor of the third ventricle can be performed by blunt penetration with the endoscope or a rigid probe, electrocoagulation, balloon catheterization, water jet fenestration, or laser coagulation. Our preference is to use a rigid probe introduced through a working channel in the endoscopesheath to puncture the floor of the third ventricle. The opening was dilated to $5-6 \mathrm{~mm}$ with a 3-Fr Fogarty balloon. Adequacy of the ventriculostomy was judged by oscillations of CSF flow through the fenestration. On completion of the ventriculostomy, the neuro-endoscope was withdrawn and the operative site was closed in layers.

\subsection{Postoperative Assessments}

Post operatively we evaluated conscious level, cranial wound, abdominal wound, Head circumference, and pumping function of the reservoir in VP shunt cases. Postoperative CT scan was done to evaluate proximal limb of the VP shunt, ventricular drainage, size and presence of any complications e.g. intra ventricular hemorrhage. MRI used to detect even slow flow through the stoma of ETV.T2 Fast-Field Echo sequence was done for cysts detection and assessment of CSF pathways patency.

\subsection{Statistical Analysis}

All data were statistically analyzed through statistical package of (SPSS) software version 13.0. We set a $P$ value above 0.05 is considered significant

\subsection{Limitations}

Age of the patient, cost of endoscopic instruments, duration of the study were the main limitation to our work.

\section{Results}

Fifty two infants were included, 26 infants in each group. The mean age of included patients was $11.3 \pm 4.7$ months for V-P shunt Group and $11.0 \pm 4.3$ months for ETV group. In V-P shunt group, $53.8 \%$ were males and $46.2 \%$ were females while in ETV group, $42.3 \%$ were males and $57.7 \%$ were females (Table 1 ).

\section{Operative data}

Statistically significant observed regarding operating time, In ETV group operation duration was $46.9 \mathrm{~min}$ and $64.3 \mathrm{~min}$ in the V-P shunt group $(\mathrm{P}=0.13)$. Regarding the cause of hydrocephalus, no statistically significant difference between the two study groups (Table 2).

\section{Postoperative outcomes:}

The rate of postoperative infection in the ETV group was statistically significant lower than in the V-P shunt group $23.1 \%$ versus $53.8 \%(\mathrm{P}=0.045)$. While there was no statistically significant difference between the two study groups re- 
garding the rate of obstruction, change in OFC or the need of revision surgery (Table 3).

In VP shunt group, CT brain revealing supratentoial hydrocephalus. V-P shunt was applied (Medtronic medium pressure) followed by decrease in the head circumference and laxity of anterior fontanelle, Figure 1 and Figure 2. While ETV group, MRI brain revealing tri-ventricular hydrocephalus. ETV was done followed by decrease in head circumference. Follow up CT brain was done, condition was stable up till now, Figures 3-5.

\section{One year survival}

Kaplan-Meier survival functions were calculated where 1 year survival for V-P shunt group vs. ETV group was $46.2 \%$ vs. $65.4 \%$ respectively with no statistically significant difference between the two studied groups (Figure 6).

Table 1. Characteristics of the study population.

\begin{tabular}{lcccc}
\hline \multicolumn{2}{c}{ Demographic variable } & $\begin{array}{c}\text { V-P shunt Group } \\
(\mathbf{n}=26)\end{array}$ & $\begin{array}{c}\text { ETV } \\
\text { Group }(\mathbf{n}=26)\end{array}$ & P-Value \\
\hline \multirow{2}{*}{ Age } & Mean \pm SD & $11.3 \pm 4.7$ & $11.0 \pm 4.3$ & 0.831 \\
& Range & $6-21$ & $6-20$ & \\
\multirow{2}{*}{ Gender } & Male no (\%) & $14(53.8 \%)$ & $11(42.3 \%)$ & 0.579 \\
& Female no (\%) & $12(46.2 \%)$ & $15(57.7 \%)$ & \\
\hline
\end{tabular}

Analysis of quantitative data by independent- $\mathrm{t}$ test, Analysis of qualitative data by chi-squared test, $\mathrm{P}$-value is considered significant at $<0.05$.

Table 2. Operative data regarding causes of hydrocephalus etiology and operation duration.

\begin{tabular}{ccccc}
\hline Demographic variable & $\begin{array}{c}\text { V-P shunt Group } \\
(\mathbf{n}=26)\end{array}$ & $\begin{array}{c}\text { ETV } \\
\text { Group }(\mathbf{n}=26)\end{array}$ & P-Value \\
\hline Cause & Congenital (\%) & $13(50 \%)$ & $12(46.2 \%)$ & \\
& Postmeningetic (\%) & $13(50 \%)$ & $14(53.8 \%)$ & 1.000 \\
\multirow{2}{*}{$\begin{array}{c}\text { Operation time } \\
(\text { min })\end{array}$} & Mean \pm SD & $64.3 \pm 29.5$ & $46.9 \pm 18.05$ & $0.013^{*}$ \\
\hline
\end{tabular}

Table 3. Postoperative outcomes.

\begin{tabular}{lcccc}
\hline \multirow{2}{*}{ Demographic variable } & $\begin{array}{c}\text { V-P shunt Group } \\
(\mathbf{n}=26)\end{array}$ & $\begin{array}{c}\text { ETV } \\
\text { Group (n=26) }\end{array}$ & P-Value \\
\hline \multirow{3}{*}{ Infection } & Yes (\%) & $14(53.8 \%)$ & $6(23.1 \%)$ & \\
& No (\%) & $12(46.2 \%)$ & $20(76.9 \%)$ & $0.045^{\star}$ \\
Obstruction & Yes (\%) & $11(42.3 \%)$ & $9(34.6 \%)$ & \\
& No (\%) & $15(57.7 \%)$ & $17(65.4 \%)$ & 0.776 \\
OFC & The same (\%) & $16(61.5 \%)$ & $17(65.4 \%)$ & 1.000 \\
& Increased (\%) & $10(38.5 \%)$ & $9(34.6 \%)$ & \\
Revision surgery & Yes (\%) & $14(53.8 \%)$ & $9(34.6 \%)$ & 0.264 \\
& No (\%) & $12(46.2 \%)$ & $17(65.4 \%)$ & \\
\hline
\end{tabular}




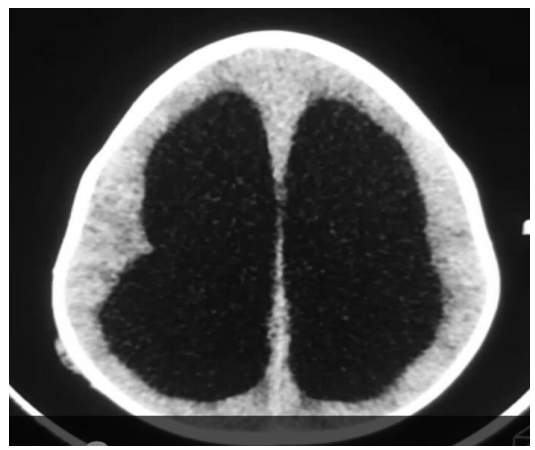

Figure 1. CT brain scan preoperative showing supra-tentorial hydrocephalus.

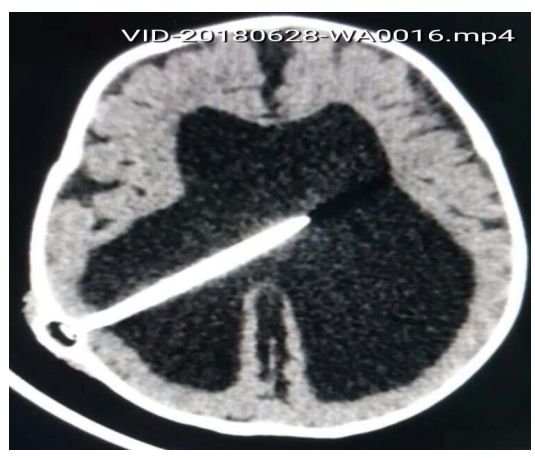

Figure 2. Follow up CT brain scan after 2 years showing right $\mathrm{V}-\mathrm{P}$ shunt.

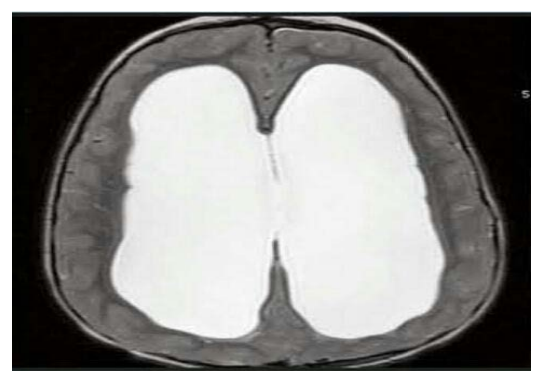

Figure 3. Preoperative MRI brain T2 done showing supra-tentorial triventricular hydrocephalus.
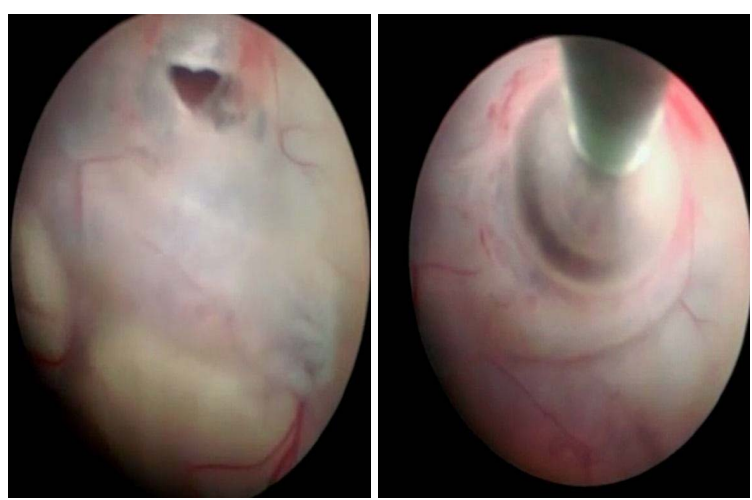

Figure 4. Intraoperative neuro-endoscopic graph, Balloon of the Fogarty catheter within the fenestration. 


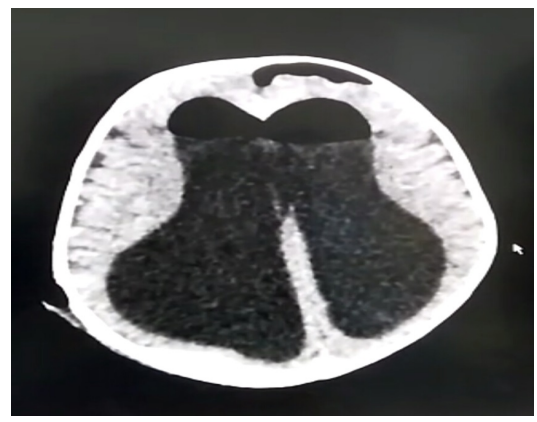

Figure 5. Follow up CT brain scan one month postoperative of ETV.

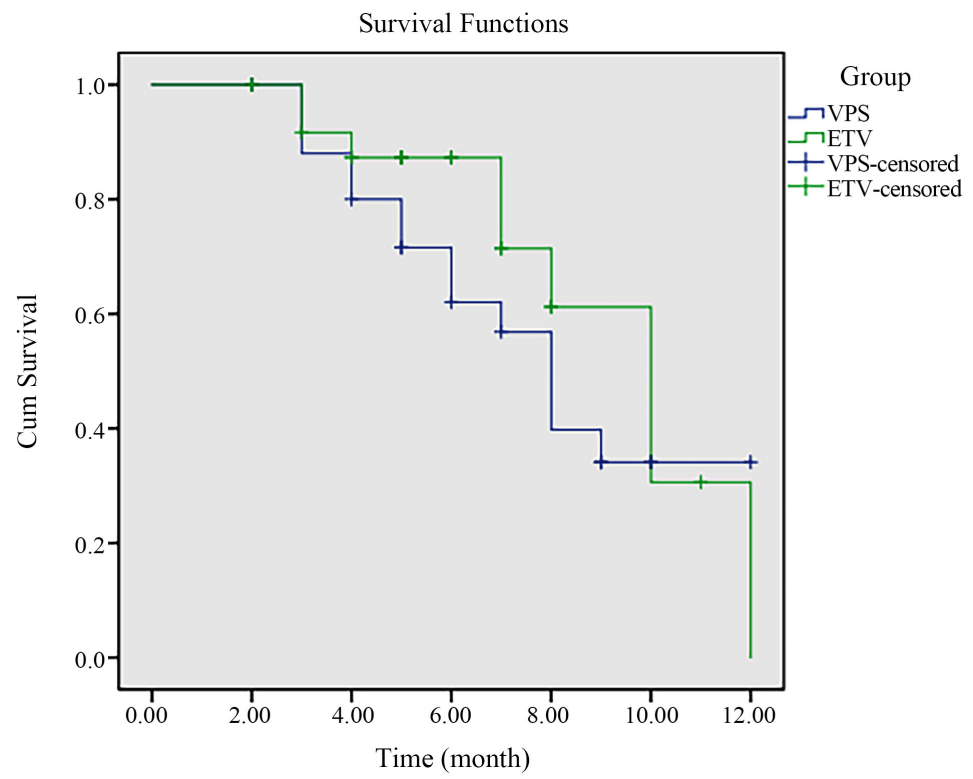

Figure 6. Kaplan-Meier-survival graph for both operative methods.

\section{Discussion}

We conducted this observational study to do comparative efficacy between endoscopic third ventriculostomy (ETV) versus ventriculo-peritoneal shunt (VP shunt) in children below two years. We found ETV was associated with shorter operation time and lower rate of postoperative infection compared to VP shunt. No significant difference observed between ETV and VP shunt regarding obstruction rate, change in OFC, need of revision surgery or etiology of hydrocephalus.

Several studies compared between ETV and VP shunt, Limbrick Jr DD, et al. 2014 conducted a systematic review and showed similar rate of surgical failure observed in the two procedures [10]. A recent meta-analysis conducted in 2018 by Saekhu concluded none of the two surgeries was superior to each other after one year of follow up [11]. Another robust meta-analysis by Jiang 2018 found ETV had lower rates of complication, infection, and reoperation, shorter duration of surgery and hospital stay but showed similar result regarding incidence of symptom improvement, hematoma, and mortality compared to VP shunt 
[12]. The difference in both meta-analyses may be due to sample size as Jiang included 2017 patients while Saekhu included 1513 besides differences in reported outcomes in both studies.

Uche EO 2018 conducted prospective cohort compared between ETV and VP shunt in children with non-communicating hydrocephalus and showed VPS is associated with an earlier milestone and OFC response while ETV is associated with lower rates of sepsis and mortality [13]. Systematic review by Dewan MC 2017 concerned with children with hydrocephalus following posterior fossa tumor resection showed ETV has long-term treatment durability and sooner failure rate but was associated with lower incidence of complications compared to VP shunt [14].

Drake 2009 and Tuli 2000 showed that age is a major prognostic factor in surgery failure. Drake claimed higher failure rates occur in younger infants. This may be attributed to children thin skin, immaturity of immune system and higher rate of CSF to leak out [15]. Tuli found age at the time of shunt placement and time since previous surgery revision is a major predictors of surgery failure [16]. A retrospective analysis of 5416 infants by Jernigan 2014 on infants with hydrocephalus younger than one year showed ETV has higher failure rates compared to VP shunt [17].

Meta-analysis by Saekhu 2018 showed the duration of follow up may affect the surgery outcomes. Drake reported early follow up data showed ETV has higher failure rates while after three months follow up ETV failure rate was lower than shunt surgery [15]. Saekhu 2018 showed after one year follow up ETV and VP shunt have a similar failure rate [11].

Many factors reported in the previous studies may affect surgery result as surgeon skills, cost of surgery and surgery instruments. Lima et al. 2014 concluded that ETV is not higher than VP shunt but nearly the same as another operation is needed in children due to shunt failure [18].

The largest study of ETV success in very young children was conducted in Uganda and involved 153 children younger than one year. The ETV success rate among these patients was $53 \%$. The surgery success rates for patients with myelomeningocele and aqueductal obstruction were higher (70\%) [19].

There is a little evidence in literature to support the superiority ETV or VPS. Most of the available studies are observational studies and limited in sample size. We recommend future larger studies with longer periods of follow up to be conducted.

\section{Conclusion}

ETV associated with lower rates of postoperative infection and shorter operation time with no significant difference in rates of obstruction, change in OFC and revision surgery in comparison to VP shunt.

\section{Conflicts of Interest}

The authors declare no conflicts of interest regarding the publication of this paper. 


\section{References}

[1] Campos, L.G., Menegatti, R. and Vedolin, L.M. (2016) Hydrocephalus in Children. In: Critical Findings in Neuroradiology, Springer, Berlin, 255-263. https://doi.org/10.1007/978-3-319-27987-9 27

[2] Wang, S., Muir, R. and Warf, B. (2016) Global Surgery for Pediatric Hydrocephalus in the Developing World: A Review of the History, Challenges, and Future Directions. Neurosurgical Focus, 41, E11. https://doi.org/10.1017/cjn.2017.113

[3] Sakka, L., Coll, G. and Chazal, J. (2011) Anatomy and Physiology of Cerebrospinal Fluid. European Annals of Oto-Rhino-Laryngology, Head and Neck Diseases, 128, 309-316. https://doi.org/10.1016/j.anorl.2011.03.002

[4] Oi, S. (2011) Classification of Hydrocephalus: Critical Analysis of Classification Categories and Advantages of "Multi-Categorical Hydrocephalus Classification" (Mc HC). Child s Nervous System, 27, 1523-1533. https://doi.org/10.1007/s00381-011-1542-6

[5] Tully, H.M. and Dobyns, W.B. (2014) Infantile Hydrocephalus: A Review of Epidemiology, Classification and Causes. European Journal of Medical Genetics, 57, 359-368. https://doi.org/10.1016/j.ejmg.2014.06.002

[6] Frim, D.M., Scott, R.M. and Madsen, J.R. (1998) Surgical Management of Neonatal Hydrocephalus. Neurosurgery Clinics of North America, 9, 105-110.

http://www.ncbi.nlm.nih.gov/pubmed/9405768 https://doi.org/10.1016/S1042-3680(18)30283-3

[7] Sgouros, S., Malluci, C., Walsh, R. and Hockley, A.D. (1995) Long-Term Complications of Hydrocephalus. Pediatric Neurosurgery, 23, 127-132.

https://doi.org/10.1159/000120949

[8] Hader, W.J., Walker, R.L., Myles, S.T. and Hamilton, M. (2008) Complications of Endoscopic Third Ventriculostomy in Previously Shunted Patients. Neurosurgery, 63, ONS168-74. https://doi.org/10.1227/01.NEU.0000310762.26035.B0

[9] Ogiwara, H., Dipatri, A.J., Alden, T.D., Bowman, R.M. and Tomita, T. (2010) Endoscopic Third Ventriculostomy for Obstructive Hydrocephalus in Children Younger than 6 Months of Age. Child s Nervous System, 26, 343-347. https://doi.org/10.1007/s00381-009-1019-Z

[10] Limbrick, D.D., Baird, L.C., Klimo, P., Riva-Cambrin, J. and Flannery, A.M. (2015) Pediatric Hydrocephalus: Systematic Literature Review and Evidence-Based Guidelines. Part 4: Cerebrospinal Fluid Shunt or Endoscopic Third Ventriculostomy for the Treatment of Hydrocephalus in Children. Journal of Neurosurgery: Pediatrics, 14, 30-34. https://doi.org/10.3171/2014.7.PEDS14324

[11] Saekhu, M., Pujiastono, E.S. and Santoso, F. (2018) Endoscopic Third Ventriculostomy (ETV) versus Ventriculoperitoneal Shunt (VPS) for Pediatric Hydrocephalus: A Meta-Analysis. Indonesian Journal of Neurosurgery, 1, 10-18. https://doi.org/10.15562/ijn.v1i1.14

[12] Jiang, L., Gao, G. and Zhou, Y. (2018) Endoscopic Third Ventriculostomy and Ventriculoperitoneal Shunt for Patients with Noncommunicating Hydrocephalus: A PRISMA-Compliant Meta-Analysis. Medicine (Baltimore), 97, e12139. https://doi.org/10.1097/MD.0000000000012139

[13] Uche, E.O., Okorie, C., Iloabachie, I., Amuta, D.S. and Uche, N.J. (2018) Endoscopic Third Ventriculostomy (ETV) and Ventriculoperitoneal Shunt (VPS) in NonCommunicating Hydrocephalus ( $\mathrm{NCH}$ ): Comparison of Outcome Profiles in Nigerian Children. Child s Nervous System, 34, 1683-1689.

https://doi.org/10.1007/s00381-018-3848-0 
[14] Dewan, M.C., Lim, J., Shannon, C.N. and Wellons, J.C. (2017) The Durability of Endoscopic Third Ventriculostomy and Ventriculoperitoneal Shunts in Children with Hydrocephalus Following Posterior Fossa Tumor Resection: A Systematic Review and Time-to-Failure Analysis. Journal of Neurosurgery. Pediatrics, 19, 578584. https://doi.org/10.3171/2017.1.PEDS16536

[15] Drake, J.M., Kulkarni, A.V. and Kestle, J. (2009) Endoscopic Third Ventriculostomy versus Ventriculoperitoneal Shunt in Pediatric Patients: A Decision Analysis. Child $s$ Nervous System, 25, 467-472. https://doi.org/10.1007/s00381-008-0761-y

[16] Tuli, S., Drake, J., Lawless, J., Wigg, M. and Lamberti-Pasculli, M. (2009) Risk Factors for Repeated Cerebrospinal Shunt Failures in Pediatric Patients with Hydrocephalus. Journal of Neurosurgery, 92, 31-38. https://doi.org/10.3171/jns.2000.92.1.0031

[17] Jernigan, S.C., Berry, J.G., Graham, D.A. and Goumnerova, L. (2014) The Comparative Effectiveness of Ventricular Shunt Placement versus Endoscopic Third Ventriculostomy for Initial Treatment of Hydrocephalus in Infants. Journal of Neurosurgery: Pediatrics, 13, 295-300. https://doi.org/10.3171/2013.11.PEDS13138

[18] Lima, B.O. and Pratesi, R. (2014) Endoscopic Third Ventriculostomy Has No Higher Costs than Ventriculoperitoneal Shunt. Arquivos de Neuro-Psiquiatria, 72, 524-527. https://doi.org/10.1590/0004-282X20140070

[19] Warf, B.C. (2005) Hydrocephalus in Uganda: The Predominance of Infectious Origin and Primary Management with Endoscopic Third Ventriculostomy. Journal of Neurosurgery, 102, 1-15. https://doi.org/10.3171/ped.2005.102.1.0001 